Article

\title{
Pueblos indígenas y religiosidad en México frente a la pandemia por COVID-19 ${ }^{1}$
}

\author{
Jorge Valtierra Zamudio², Lorena Córdova-Hernández ${ }^{3}$
}

\begin{abstract}
Resumen. La pandemia de COVID-19 ha mostrado efectos adversos en el mundo, no sólo en el aspecto socioeconómico sino también en las prácticas religiosas, las cuales son fundamentales para la cohesión y afirmación de la identidad de los pueblos indígenas. En México, los mecanismos de adaptación a la contingencia sanitaria, en este caso del catolicismo, se han destacado por el uso de las tecnologías de la información y la comunicación. Sin embargo, en las comunidades indígenas (rurales) no existe la infraestructura necesaria para lograr trasladar las prácticas religiosas a dichos formatos. En consecuencia, algunas comunidades suspendieron estas actividades y otras continuaron de forma autónoma, a pesar de la contingencia sanitaria, porque la actividad religiosa es esencial para protegerse y enfrentar eventos como la pandemia. Este artículo describe - a través de la aplicación de entrevistas de telefónicas y seguimiento de los espacios de comunicación de las comunidades y misiones católicas - cómo se modificó la experiencia religiosa de algunas comunidades tojolabales en el estado de Chiapas y una comunidad ixcateca en el estado de Oaxaca. Asimismo, cómo las comunidades indígenas siguen o no sus prácticas espirituales y cómo la religión juega un papel fundamental en las comunidades indígenas mexicanas a pesar del confinamiento y distancia social en el marco de la pandemia.
\end{abstract}

Palabras clave: COVID-19, Religión; catolicismo, tojolabal; ixcateco.

\begin{abstract}
The COVID-19 pandemic shows adverse effects around the world, not only in the socio-economic aspect but also in religious practices, which are fundamental for the cohesion and affirmation of the identity of indigenous peoples. In Mexico, the forms that Catholicism has adopted to adapt to the health contingency stand out for the use of information and communication technologies. However, in indigenous (rural) communities, there is not enough infrastructure to transfer religious practices to these formats. Consequently, some villages suspended these activities, while others continued autonomously, despite the health contingency, that is because religion is fundamental to protect themselves and face events such as the pandemic. This article describes - through the application of telephone interviews and monitoring of the communication spaces of the Catholic communities and missions - how the religious experience of some Tojolabal peoples in Chiapas and an Ixcatecan village in Oaxaca. Likewise, how indigenous communities follow their spiritual practices or not and how
\end{abstract}

\footnotetext{
${ }^{1}$ La investigación fue financiada por el proyecto no. 3035 "Revitalización de lenguas y culturas fronterizas en riesgo de desaparición: documentación, planificación y colaboración comunitaria” de la Convocatoria Fronteras de la Ciencia de Conacyt, México.

${ }^{2}$ Profesor investigador Universidad La Salle, México. E-mail: jorge.valtierra@lasalle.mx

${ }^{3}$ Profesora investigadora Universidad Autónoma Benito Juárez de Oaxaca. E-mail: lcordova.cat@uabjo.mx
} 
religion plays a fundamental role in Mexican indigenous communities despite confinement and social distance in the context of the pandemic.

Keywords: COVID-19, Religion, Catholicism, Tojolabal, Ixcatec.

\section{Introducción}

En México, los pueblos indígenas (PI) son considerados como el sector social más excluido y discriminado. Éstos ascienden a 27.5 millones; es decir, el $21.5 \%$ de la población (IWGIA, 2019). ${ }^{4}$ La pandemia por SARS-CoV-2, además del impacto en la salud de la sociedad mexicana, visibilizó su condición de desigualdad social y con ello la amenaza a su condición y permanencia sociocultural, ya de por sí vulnerable. Desde la ciencias sociales y humanidades, los PI remiten a un pasado de dominio, transculturación e imposición ideológica y religiosa que explica parte de su situación actual.

Sin embargo, Dussel (1998) advierte que el entramado simbólico entre el cristianismo y las religiones prehispánicas originaron el catolicismo latinoamericano, y esta síntesis nutre el carácter religioso de los PI. Para los PI, la religión tiene una función primordial, pues es la forma en que resuelven o se protegen de adversidades como desastres, enfermedades, desempleo, etc., lo cual se ve en los altares que configuran con efigies, afiches, veladoras u otros elementos con la imagen de la Virgen de Guadalupe, San Judas Tadeo y otros personajes taumatúrgicos a quienes se encomiendan.

En los rituales y prácticas religiosas de los PI de México hay elementos que no son de origen cristiano. Es común encomendarse a una entidad divina para obtener una buena cosecha, como en el caso de los tojolabales que rezan al Padre Eterno, que es tanto Dios (católico), como el "rayo" asociado a la lluvia y la protección de su cosecha (Ruz, 1982). Otros ejemplos son las fiestas patronales, el k'in santo (día de muertos) o el ta’an k’oy (carnaval) que, además de su función de protección mantiene viva la memoria y reafirma la religiosidad e identidad tojolabal como pilar de su estructura social. ${ }^{5}$

La pandemia por COVID-19 ha modificado muchas dinámicas sociales y religiosas. Muchos de los repertorios y rituales religiosos (festividades, peregrinaciones y rezos colectivos) presentan de suyo características contrarias a las medidas de distancia sanitaria, Empeora el escenario si se considera la participación de gente que proviene de otras localidades, lo que favorece la propagación del virus.

Al respecto, las asociaciones religiosas en México, (evangélicos, pentecostales, católicos, etc.), se alinearon a las disposiciones sanitarias de las autoridades de salud mexicanas, cerraron templos y cancelaron celebraciones, aún con alguna reticencia al principio por parte de algunas iglesias (Corpus, 2020). Entre agosto y septiembre de 2020 en algunos estados con una fase epidemiológica en naranja y una disminución de contagios, se tomó

\footnotetext{
${ }^{4}$ Muchos de los PI se han visibilizado a partir del uso de su lengua como elemento de diferenciación étnica, aunque en mucha de la información estadística y demográfica de otras épocas se les negaba esa categoría. Desde esta perspectiva, la población indígena conforma el 6.5\% de la población mexicana (7.4 millones de individuos). Sin embargo, en México estos grupos tienen una situación de desplazamiento lingüístico alarmante, por lo que muchos han dejado de utilizar o transmitir la lengua, aunque siguen reconociéndose como indígenas.

${ }^{5}$ Cabe destacar que su religiosidad no impide la división comunitaria, sobre todo, por la llegada de más grupos religiosos a los que algunos se adscriben, lo que genera enemistad y desorganización intracomunitaria.
} 
la decisión de mantener cerrados algunos templos o abrir otros con algunas medidas preventivas - separación de asientos, disposición de gel antibacterial, sanitización del recinto y uso de mascarillas-. Pero muchos rituales (misas, alabanzas, etc.) aún se realizan de forma remota a través de plataformas como Facebook Live, Zoom, entre otros. En los PI, el problema de estas alternativas son:

1. Falta de acceso a dispositivos y, en muchos casos, servicio de internet.

2. Poca adaptación, según el grupo generacional, a las formas de transmisión de ceremonias y días festivos.

3. Imposibilidad de llevar a cabo fiestas religiosas so pena de contagio; la ausencia del sacerdote o pastor $\mathrm{y}$, sobre todo, la restricción para entrar a las comunidades para evitar contagios.

4. Ausencia de derrama económica que, en condiciones normales, se daba con las ferias y vendimias características en estas fiestas.

Como puede observarse, el efecto de la pandemia por COVID-19, tiene una naturaleza variada que afecta en diferentes puntos a los PI, pero también a los organismos eclesiásticos. La pregunta no sólo es cómo resolver esta situación, sino ¿cómo se han organizado, tanto comunidades indígenas como los organismos eclesiásticos, para continuar con la actividad religiosa que es un factor que forma parte de la estructura sociocultural de los PI?

Este artículo analiza las formas de organización de dos PI en el sur de México para enfrentar la pandemia por COVID-19. En particular, la manera en que han modificado o adaptado sus tradiciones religiosas ante una situación de emergencia sanitaria, lo que alude a ser la comunidad la que determina y administra sus prácticas religiosas.

El enfoque de esta investigación estará en la Iglesia católica y su relación con el grupo indígena ixcateco del estado de Oaxaca y el tojolabal del estado de Chiapas. En primer lugar, se esbozará la importancia y función de la religión y las prácticas religiosas para los grupos indígenas católicos. Después, a partir del caso de los ixcatecos y tojolabales, con base en información obtenida a través del trabajo de campo realizado desde hace una década e información vía telefónica con autoridades y agentes de pastoral en ambas entidades, se explicarán las medidas y formas de organización de estas comunidades en relación con las actividades religiosas que llevan a cabo por tradición entre el mes de febrero y septiembre, frente a la coyuntura de la pandemia, así como la postura y acción de la Iglesia católica en relación con estas sociedades. Para cerrar, se expondrán las consecuencias y proyecciones que manifiestan para sostener o, incluso posponer, estos eventos religiosos, una vez pasada la contingencia sanitaria.

\section{La función de la religión en tiempos de COVID-19}

En México, durante el tiempo de confinamiento las opiniones en redes sociales tratan de evidenciar que la religión no es útil ante situaciones como la pandemia por COVID-19. Entre algunos comentarios sarcásticos y otros con fines políticos y ajenos al tema de COVID-19 - escándalos de asociaciones religiosas como la detención del líder de La Luz del Mundo por abuso sexual a menores o casos de pederastia por sacerdotes católicos- es evidente el cuestionamiento del papel de los líderes religiosos y de la religión misma.

Bayer (2006) sostiene que la religión ha fungido como un elemento ideológico y político al servicio del imperialismo occidental moderno, "que ha buscado la universalización de su 
peculiar perspectiva del mundo y, de este modo, controlar otras poblaciones" (Bayer, 2006, p. 12). Desde esta mirada la religión es una construcción social contingente. Pero también debe considerarse su relación con la devoción humana, conducta y actitud hacia lo sobrenatural, y no sólo pensarla como homogénea y global; también es subjetiva y autoreflexiva o "[como] procesos de interiorización y racionalización de los fenómenos religiosos y en particular la introducción de criterios y de imperativos éticos" (Bourdieu, 1971, p. 301).

Para Houtart (2002) la religión, desde un escenario que caracteriza la individualidad de los habitantes del mundo y su colectividad al mismo tiempo, se refiere a los sectores socioculturales y socioeconómicos; es decir, un escenario socialmente fragmentado para el que la religión da respuestas que se diversifican según cada "clase social" como el pentecostalismo para los sectores desfavorecidos y populares, el Opus Dei para sectores elitistas que refuerzan su sentido de excelencia de las clases dominantes, o la "revitalización" de la religiosidad indígena alrededor del mundo, como una forma de expresión de la recuperación de una identidad perdida (Houtart, 2002).

Finalmente, hay una parte emocional de donde nace la religión y la experiencia de lo sagrado. A diferencia de la concepción sociocultural de Houtart, la noción imperativa y normativa de Bourdieu o la explicación de dominación homogénea y global de Bayer, también cabe pensarse en una función, a la vez individual y colectiva, para concebir al mundo, por lo que tiene una carga de símbolos sistematizados que formulan "concepciones de un orden general de existencia y [...] efectividad tal que los estados anímicos y motivaciones parezcan de un realismo único" (Geertz, 1989, p. 89).

En este sentido, el cristianismo ha tenido un papel de unidad y construcción social a través del cual se conforma una serie de principios y normas éticas en una sociedad, prescripciones morales específicas que rigen la rutina de la vida cotidiana; pero también se ha ido adaptando a la forma de concebir el mundo desde los símbolos y códigos culturales de una sociedad determinada, por lo que en la actualidad el cristianismo es la forma en la que muchos pueblos codifican su interacción, caracterizan y reafirman su identidad e individualidad, y obtienen respuestas y esperanza sobre las adversidades. Así, la religión es la aplicación de "las cuestiones más fundamentales de la existencia humana a una vida distintivamente individual” (Eagleton, 1997, p. 77), por lo tanto, de su cultura.

Al concentrarse en los PI mexicanos, pese a los elementos propios de cada población al manifestar su religiosidad, la importancia de llevar a cabo las fiestas de cada localidad -Santo Patrono, Pascua, Día de Muertos... - es porque reafirman su identidad como sociedad a través de sus tradiciones y activan su interacción con otras comunidades, pues en la mayoría de las festividades hay intercambios comerciales, atracción de visitantes de otras poblaciones y, en la organización de las festividades se generan mecanismos de reciprocidad y cohesión comunitaria. Esto implica que no se trata sólo de una naturaleza sagrada, sino sociocultural y socioeconómica de la religión.

En el sur y sureste de México se cuenta con una diversidad cultural y lingüística que se manifiesta también en sus costumbres religiosas. Sería un trabajo inalcanzable abordar y contrastar cada uno de estos rasgos religiosos y culturales, cuando hablamos, por ejemplo, del estado de Oaxaca con dieciséis grupos étnicos y el estado de Chiapas con trece. Por esta razón, se ha elegido el caso de los ixcatecos del municipio de Santa María Ixcatlán, que ha sido poco trabajado en la temática religiosa oaxaqueña, y los tojolabales de los municipios de Las Margaritas y Altamirano, en Chiapas que contrasta con el caso ixcate- 
co. Durante la cuarentena, en Ixcatlán se decretó el cierre de la comunidad, mientras que en las comunidades tojolabales no fue así, aunque se mantuvo comunicación con la Iglesia católica a través de la Misión de Guadalupe, en la ciudad de Comitán.

Antes de desarrollar estos casos, cabe aclarar que la posición de la Iglesia católica al respecto, va desde una interpretación de la pandemia un tanto apocalíptica; es decir, es una advertencia divina por el comportamiento del ser humano, y en la prensa mundial se lee el COVID-19 como el principio del Apocalipsis en una suerte de teoría de la conspiración (Rivera, 2020 y Navalón, 2020), lo que ha sido negado por algunos expertos en teología, aunque no de manera contundente. Mucho del fundamento de estas interpretaciones, como se lee en una nota del New York Times, se articula con otros fenómenos globales que relacionan con el contenido del Antiguo Testamento (Dias, 2020).

Pero para la Iglesia católica, más allá de explicar el COVID-19 como castigo divino, según han expresado algunos jerarcas como Felipe Arizmendi, obispo de la diócesis de San Cristóbal (Calderón, 2020) o Ramón Castro, obispo de Cuernavaca, (La Jornada, 2020), han acatado las recomendaciones de la autoridad sanitaria de mexicana y han suspendido sus actividades pública.

Los dispositivos virtuales para acceder a la feligresía no son eficientes en contextos rurales indígenas, y es difícil saber por el confinamiento cómo se ha dado seguimiento a la actividad pastoral durante la contingencia o cómo se han organizados los pobladores para enfrentar esta situación. A partir de los casos arriba mencionados se explicará a continuación qué sucede en estas localidades rurales y alejadas de la actividad religiosa de la Iglesia católica.

\section{La situación religiosa en la pandemia: tojolabales e ixcatecos frente al COVID-19}

La mayoría de las comunidades indígenas en México se ubican en un contexto rural y al interior de éstas es común ver organismos o iglesias de distintas confesiones de fe. En estos casos también las actividades religiosas se suspendieron por no ser una actividad esencial, como establece la Jornada Nacional de Sana Distancia de la Secretaría de Salud del Gobierno de México, pues sólo se consideran esenciales actividades del sector de la salud y abastecimiento de productos básicos (Corpus, 2020). Además, la mayoría de la actividades religiosas son colectivas, por lo que estimulan la propagación del virus.

Los casos ixcateco y tojolabal tienen en común el contexto rural, además de ser casos poco documentados desde la perspectiva religiosa y cultural, a diferencia de otros PI. En ambos contextos, lo que se observa de forma general es una situación de vulnerabilidad frente a la pandemia.

Los ixcatecos, como muchos PI de la sierra de Oaxaca, cerraron el paso a sus comunidades y suspendieron actividades y festividades religiosas como medida de protección. El caso tojolabal es distinto porque no cerraron muchas comunidades, aunque es cierto que frente a la escasez laboral por la contingencia, varios de los migrantes regresaron desde hace tiempo a sus comunidades de origen y no tienen un contacto muy constante con las ciudades. Si bien ha habido contagios, éstos han sido mínimos y los pobladores expresan haber tenido síntomas de temperatura alta y tos, pero con una recuperación exitosa con base en la herbolaria, según informa una agente de pastoral de la Misión de Guadalupe en Comitán, Chiapas (Conversación telefónica con María Bernarda, 25 de agosto de 2020). 
Estos escenarios distintos son ejemplos que deben desarrollarse por separado para comprender la realización de sus actividades religiosas en medio de la pandemia por Covid-19 y el papel de la Iglesia católica.

\subsection{El pueblo ixcateco y el Señor de las Tres Caídas}

Santa María Ixcatlán es un municipio del estado de Oaxaca que, según el Instituto Nacional para el Federalismo y el Desarrollo Municipal (2010), cuenta con $189.93 \mathrm{~km}^{2}$, con escasos ríos y clima cálido y una población de 462 individuos (INPI, 2020). En la localidad de Santa María Ixcatlán habitan los últimos hablantes de ixcateco, de los que quedan ocho y éstos son de edad avanzada. El desplazamiento lingüístico y cultural es grave, además de manifestar una situación demográfica caracaterizada por la alta actividad migratoria en busca de empleo y/o continuar con los estudios de bachillerato.

En realidad, no puede asumirse su condición como marginal, pues cuentan con servicios básicos y una buena organización comunitaria, cumpliendo con lo señalado en la Ley General de Desarrollo Social para definir la pobreza (Capítulo IV, artículo 36), a saber: cohesión social, seguridad social, calidad y acceso a los servicios de salud, etc., aunque en otros aspectos sí puede percibirse alguna situación de rezago como educación, alimentación nutritiva y de calidad, y la accesibilidad por medio de carretera pavimentada, la cual está en proceso de construcción.

El clima no es propicio para el desarrollo agrícola debido al avanzado proceso de desertificación de la zona, por lo que sus principales actividades son el tejido de la palma para la elaboración de sombreros y petates, y la producción artesanal de mezcal de agave papalomé o tobalá silvestre. ${ }^{6}$

Sus tradiciones y festividades se concentran en el Señor de las Tres Caídas que se celebra el cuarto viernes de cuaresma. Aquí participan los pobladores de Santa María Ixcatlán y peregrinos que visitan el santuario de distintas partes de la República. También celebran la fiesta de la Coronación del Señor de las Tres Caídas llevada a cabo el 7 de mayo (Inafed, 2010). La primera celebración se realizó entre el 16 y el 20 de marzo de 2020, pero la Coronación del 7 de mayo se suspendió porque ya se había declarado la situación sanitaria del país como grave desde antes de la Semana Santa.

La importancia de estas festividades no sólo genera una interacción vital para una comunidad que se encuentra muy alejada de otras poblaciones, y con ello un intercambio cultural, sino que es un momento importante por la feria misma que incluye prácticas de compraventa; esto es, un mercado con una derrama económica importante complementaria a la labor artesanal de los pobladores de la que, además de las remesas y recursos obtenidos por familiares que trabajan fuera de Ixcatlán, dependen varias familias.

La celebración y naturaleza religiosa del evento conlleva una compleja estructura económica y social que se ha visto frenada por la pandemia, como se lee en un documento oficial de la comunidad publicado en la página de Facebook oficial de Ixcatlán (imagen

\footnotetext{
${ }^{6}$ Destaca el hecho de no ser un maguey cultivado, sino silvestre. Éste se extrae para hacer un mezcal de excelente calidad, pero, al ser una planta que tarda cerca de 10 años en crecer el producto ha escaseado, por lo que algunos productores de la comunidad ya empiezan a cultivarlo. Debe aclararse que esta no es la principal actividad de la comunidad, pues sólo algunos tienen un palenque (donde se elabora el mezcal) y tierras cultivables para el agave (Notas de campo, agosto 2019).
} 
Imagen 1. Fuente: https://www.facebook.com/NjaniMaleXulaOficial/.

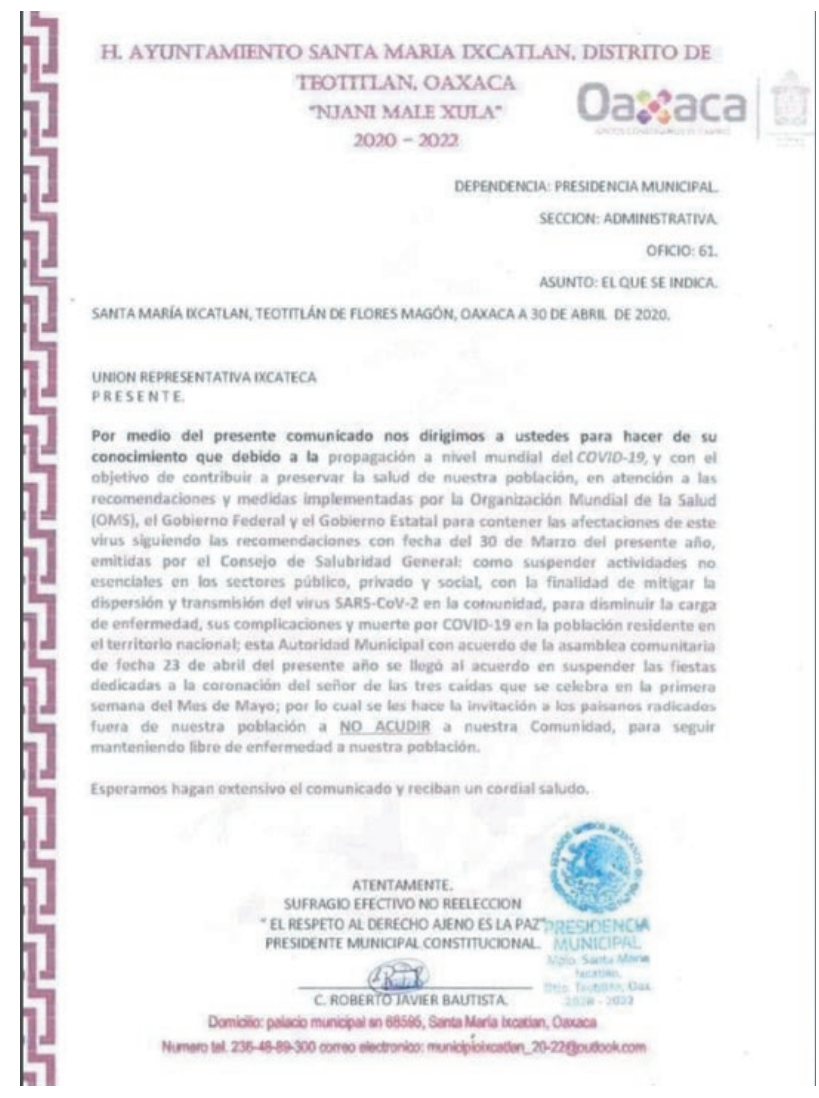

1), donde se da a conocer que, debido a la propogación del COVID-19, se determinó suspender las fiestas dedicadas a la Coronación del Señor de las Tres Caídas. Al respecto, es interesante observar el manejo de las redes sociales de las autoridades de la comunidad, porque significa que, como es el caso de otras comunidades indígenas de Oaxaca, cuentan con servicios de internet, lo que llega a ser muy útil para informar a la población migrante sobre los asuntos generales de la comunidad, así como a los devotos del Señor de las Tres Caídas que habitan, incluso en otros estados del país para evitar que se encuentren con la población cerrada.

A pesar del acceso a las redes sociales, el wifi, incluso tecnología como smartphones entre algunos de los pobladores jóvenes, no significa que sea de uso común entre todos los habitates ixcatecos. Además, no se asegura que el uso de estos dispositivos sirvan para sustituir un evento religioso como la Coronación del Señor de las Tres Caídas, debido a que:

- La fiesta de la Coronación del Señor de las Tres Caídas no se constriñe en la captación de la imagen del ritual por sí sola, sino los mecanismos de intercambio y socialización de los devotos, la feria o el mercado. 
- Los servicios que presta la Iglesia católica como proyectar las misas vía remota, implica también una cultura hacia estos dispositivos, por lo que no son un medio eficiente para paliar la ausencia de una peregrinación o ritual colectivo.

- El uso de esta tecnología y las redes sociales tienen un objetivo informativo dirigido a un público que está fuera Santa María Ixcatlán.

Cabe aclarar que los asuntos religiosos (exclusivamente católicos) ${ }^{7}$ en esta comunidad son administrados por los encargados dentro de la misma comunidad; es decir, similar a la figura del mayordomo; toda vez que se trata de un santuario por lo que no hay un diácono o presbítero permanentemente. Por esta razón, las autoridades de la comunidad son las que determinaron suspender cualquier actividad que comprometa la integridad de la población, en la misma sintonía de las jerarquías eclesiásticas durante este periodo de contingencia.

Lo que es evidente en esta y otros PI de Oaxaca, es el acatamiento de las medidas sanitarias del estado de Oaxaca y, con probabilidad, las recomendaciones y mensajes de la Iglesia católica de respetar las medidas sanitarias recomendadas por la Secretaría de Salud, así como una invitación a no temer a la pandemia y actuar con responsabilidad. Sin embargo, si se considera la práctica de la ritualidad, las festividades de los santos patronos y otros eventos religiosos en las poblaciones indígenas y no indígenas, la organización, las medidas de prevención y otras iniciativas para sobrevivir a la pandemia, son en la mayoría de los casos ajenas a este organismo eclesiástico.

\subsection{Organización religiosa entre los tojolabales en Chiapas}

En el estado de Chiapas, la población tojolabal abarca los municipios de Las Margaritas, Comitán, Altamirano, Maravilla Tenejapa, Ocosingo, La Independencia y La Trinitaria, que forman parte del sureste del estado de Chiapas. Se calcula una población de 74,924 tojolabales, considerando que muchos se encuentran fuera de su lugar de origen trabajando, según información censal de 2015 (INPI, 2020).

A diferencia de los ixcatecos con una población demarcada sólo en la localidad de Santa María Ixcatlán, los tojolabales habitan varios municipios y la presencia religiosa se adscribe a varias asociaciones religiosas y no sólo al catolicismo. De hecho, la presencia del catolicismo en algunas poblaciones es inexistente.

Los tojolabales se caracterizan por ser sumamente religiosos y lo manifiestan desde su cultura, aunque en muchos casos, según su adscripción religiosa han suprimido cierto rituales por considerarse prácticas paganas. También hay tojolabales que manifiestan su religiosidad con elementos que rememoran algún ritual de un pasado remoto junto con elementos cristianos, en una forma de sincretismo.

Mario Humberto Ruz (1982) explicaba que la historia de los tojolabales, similar al caso ixcateco, ha sido de dominio y sujeción por diferentes grupos a lo largo de la historia y, por lo tanto, de convivencia con su "dominadores". Esto podría explicar la razón por la que la mayoría de sus manifestaciones religiosas precolombinas fueron erradicadas casi por completo. Pero entre las manifestaciones religiosas principales de los tojolabales

\footnotetext{
${ }^{7}$ Santa María Ixcatlán no presenta otras iglesias no católicas. Sólo tiene un santuario y el total de la población es católica.
} 
están las romerías o peregrinaciones que llevan a cabo a diferentes puntos: la romería de San Caralampio al Barrio de la Pila en Comitán que se lleva a cabo en febrero; la de Santo Tomás Oxchuk en abril; la de San Bartolo en Venustiano Carranza y, sobre todo, aquella a su lugar mítico de origen que es San Mateo Ixtatán, en Guatemala, en donde hay minas de sal, elemento importante para curar enfermedades, hacer conjuros o propiciar abundancia (Ruz, 1982, p. 54), pero también por el símbolo de la sal que se usa antes de la siembra para obtener una buena cosecha (Furbee, 1976). ${ }^{8}$

Hay muchos rituales que siguen realizando en relación con la fertilidad de la tierra. Un ejemplo es la población de Candelaria Bienes Comunales, donde llegan a usar una gallina negra que degüellan y con su sangre riegan la milpa para que haya buena cosecha (Notas de campo, 06 de noviembre de 2010). En otras comunidades como Lomantán, la gente se encomienda al chawuk (rayo), el cual relacionan con el agua o la lluvia y también le llaman Padre Eterno (Notas de campo, 15 de noviembre de 2010).

Es interesante la forma en que elementos de la naturaleza como la sal o el agua se relacionan con algo divino entretejido con elementos cristianos, sean algunos santos o Dios. El caso de la romería de San Caralampio en Comitán es ilustrativo de esto. Mientras la población comiteca se encomienda a este santo para protegerlos de la pandemia (Expreso de Chiapas, 2020); para los tojolabales tiene un significado más, pues es una tradición antigua que implica un punto de encuentro donde interactúan tojolabales de distintas zonas y donde se da una práctica mercantil como en Ixcatlán —razón por la que en tojolabal "pueblo" o "ciudad" se dice chonab, que también significa mercado- y, más allá del santo protector, también es donde la población tiene su origen.

El punto de devoción de San Caralampio no es sólo el templo que lleva su nombre en el Barrio de la Pila, sino el punto en donde brota un manantial que alude al origen de Balún Canán (Comitán), y donde se encuentran varios símbolos sagrados para los tojolabales como una ceiba (árbol sagrado); un punto donde hay mercado donde se presentan los tojolabales con candelas, tambores, carrizos (flautas) y banderas que representan sus comunidades, y donde mantienen viva la memoria del pueblo tojolabal (Ruiz y Limón, 2019).

Las romerías son de vital importancia para los tojolabales porque se mantiene viva su identidad a través de la memoria y los mitos fundacionales, aunque llega a ser costoso, por lo que cada vez hay menos participantes de estas peregrinaciones. Por ejemplo, la que se realiza en honor a San Bartolo, en la población de Venustiano Carranza, cada vez es menos frecuente que las comunidades más alejadas hagan el recorrido. Sin embargo, es otro punto importante, en donde se encuentra el "Señor del Pozo", que también alude al elemento del agua, al chawuk, y, de la misma forma, se ora al Padre Eterno. Estas peregrinaciones, se llevan a cabo antes de la temporada de lluvias para que no falte este recurso tan importante que les da sustento a través del producto de la milpa.

Con estos ejemplos queda clara la religiosidad de los tojolabales y la importancia de eventos que implican una colectividad y movilidad. No es sólo una costumbre y un cúmulo de creencias de naturaleza sincrética, sino una manifestación esencial para su supervivencia, desde su cosmovisión, además de la interacción socioeconómica que se practica de

\footnotetext{
${ }^{8}$ Muchas de estas romerías se han dejado de realizar, debido al costo económico que implica y, por lo tanto, las prácticas religiosas se han ido modificando y realizando más en la zona en que habitan o lugares más cercanos como la Ciudad de Comitán.
} 
mucho tiempo atrás. Así, las medidas de confinamiento por la pandemia, altera significativamente su modus vivendi y su actividad religiosa.

A diferencia de los ixcatecos, muchos tojolabales no cerraron sus comunidades, ni dejaron de realizar sus actividades religiosas. La comunicación constante entre la Misión de Guadalupe y ellos, siendo respetuosos de las medidas sanitarias, muestra un seguimiento de los agentes de pastoral para saber qué ocurre y cómo enfrentan estas comunidades la pandemia. Una agente de pastoral de la misión, explica que muchos tojolabales no sólo realizaron sus actividades religiosas normales, sino que a pesar de encontrar cerrados los templos en los puntos de partida de peregrinaciones, ellos llevarían a cabo su recorrido, con o sin la Iglesia, como sería el caso de la romería a San Mateo Ixtatán en el mes de septiembre (Conversación telefónica, María Bernarda, 25 de agosto de 2020).

Las condiciones en las que viven los tojolabales en algunas comunidades, aparentemente los pone en una situación de vulnerabilidad. Pero la preparación que desde hace años han tenido con la Misión de Guadalupe y otras asociaciones civiles a través de proyectos de educación y formación de promotores de salud, ha rendido frutos. El uso de plantas medicinales y promover una cultura de prevención de la salud ha contribuido a una reducida cantidad de contagiados, la recuperación pronta de quienes enfermaron y pocos decesos (Comunicación vía telefónica, María Bernarda, 25 de agosto de 2020).

El seguimiento y apoyo de la misión a las comunidades que atiende ha sido notablemente efectiva a través de la tecnología (archivos de audio a través de whatsapp). La organización especial que los pastorales tienen en la zona viene de procesos que la misma misión ha llevado a cabo desde hace muchos años con estas comunidades con la perspectiva de no hacerlos dependientes de los programas y apoyos otorgados, sino comunidades autosuficientes. Esto explica los resultados efectivos en este contexto, pese a no haber cerrado las comunidades.

Otro motivo más por el que los tojolabales no suspendieron actividades religiosas, es porque creen que el COVID-19 es un invento de la autoridad, lo que puede asociarse a un pasado de opresión y engaño, pero también de rebelación si se piensa en la época en la que muchos formaron parte de las filas del Ejército Zapatista de Liberación Nacional (EZLN). También, se explica esto por el significado especial de sus prácticas religiosas de protección, por lo que suspenderlas afectaría, desde su perspectiva, su producción agrícola y su vida misma. He ahí la función de la religión para ellos.

\section{Conclusiones}

Se mencionó la actitud solidaria de la Iglesia católica en el marco de la pandemia al acatar las recomendaciones de la Secretaría de Salud (Arquidiócesis Primada de México, 2020). Es innegable la afectación económica de esto hacia los organismos religiosos, incluyendo la Iglesia católica, pero también han sabido adaptarse a la tecnología para garantizar sus servicios religiosos, arengar a la feligresía a no sucumbir frente a la adversidad del SARS Cov-2 y anunciar medidas de prevención que tomarán al regreso de la llamada nueva normalidad, para evitar una recaída.

Desde el 10 de agosto de 2020 muchos templos han abierto con una serie de medidas que exigen a los fieles respetar para ingresar al recinto. Sin embargo, en contextos rurales, en especial en las comunidades indígenas, existe una gran duda acerca de cómo se han 
organizado para sobrellevar la pandemia. La información que se obtuvo a través de llamadas teléfonicas a algunos habitantes de Santa María Ixcatlán en Oaxaca, así como una integrante de la Misión de Guadalupe en Comitán, Chiapas, después de haber dado un primer recorrido a las comunidades luego de mucho tiempo de confinamiento, ha sido esencial para conocer la experiencia de estas poblaciones frente a la pandemia.

En ambos casos existen diversas consecuencias a partir de la suspensión o no de la actividad religiosa y se puede comprender que la función de la religión es esencial para estos pueblos, no sólo por el aspecto espiritual, sino también social y mercantil. Para los tojolabales la necesidad de llevar a cabo estas actividades es vital como vía de protección, asegurar una buena cosecha y la seguridad de la comunidad, lo que se constata con la continuidad de las tradicionales romerías y la celebración dentro de la ermita en Semana Santa y Pascua.

Para los ixcatecos más coordinados con la autoridad civil era importante suspender actividades porque su santuario es un punto de reunión de personas de distintas partes, y pone en peligro a la población, de por sí reducida, y con gente en situación de riesgo por su edad. Aunque ellos usan también la herbolaria, el desplazamiento del conocimiento cultural es innegable. Además, cuentan con una Unidad Médica Rural del Instituto Mexicano de Seguro Social, por lo que pueden acceder a servicios médicos alópatas, de emergencia y prevención, y el personal que atiende esta Unidad es un médico y una enfermera, esta última habitante de la comunidad. Así, la información oficial en torno a la pandemia es completa y centrada en las recomendaciones de las autoridades sanitarias, por lo tanto, se acatan las medidas de prevención ante la pandemia.

En México, ya sea ignorando la pandemia o reprogramándola para un periodo de nueva normalidad, los PI ven en la religión más que un culto que se realiza por costumbre, una parte vital de su cultura y un fundamento de su identidad cultural. Las consecuencias en el caso ixcateco de la suspensión de la Coronación del Señor de las Tres Caídas, no sólo reacae en su economía, sino en sus mecanismos de interacción social. Entre muchas comunidades tojolabales que no suspendieron actividades religiosas y piensan seguir realizándolas, las consecuencias sobre su salud, aún son inciertas. La posibilidad de contagio en los PI no son tan agudas como en la ciudad, pues muchas comunidades fueron cerradas; tampoco lo es en términos de alimentación, pues pueden vivir de lo que producen en el campo. La afectación económica, sin embargo, se advierte en la imposibilidad de salir de sus comunidades para vender sus productos o el hecho de no encontrar fácilmente mercado para su venta.

Ahora bien, la cancelación de actividades religiosas como las fiestas de los santos patronos y similares implica la imposibilidad de estos mercados que son indispensables para su economía e interacción como una forma esencial de su estructura comunitaria y sus relaciones intercomunitarias. Estas consecuencias no están tan relacionadas con la organización, administración y suminitro de servicios religiosos como tales, pues hay una cierta autonomía de las autoridades eclesiásticas. Pero, el acompañamiento que sí tienen muchas comunidades en Chiapas, a diferencia de Oaxaca, puede ser más redituable en cuanto al proceso de resiliencia que podría incidir en la salud física y mental de las comunidades. 


\section{Fuentes}

Arquidiócesis Primada de México. (2020, 3 de junio). Orientaciones y criterios para el retorno gradual a las celebraciones litúrgicas con asistencia de fieles. Recuperado de https://arquidiocesismexico.org.mx/blog/wp-content/uploads/2020/06/Orientaciones-y-criterios-para-el-retorno-a-la-celebracion-con-presencia-de-fieles-Vd-3.pdf

Bayer, P. (2006). Definir la religión desde una perspectiva internacional: identidad y diferencia en las concepciones oficiales. Alteridades, 16(32), 11-27

Bourdieu, P. (1971). Genèse et structure du champ religieux. Revue Française de Sociologie. Centre détudes sociologiques, XII(3), 295-334

Calderón Gómez, P. (17 de abril de 2020). \#Opinión. El COVID-19 ¿Castigo de Dios?. Prensa CELAM. Recuperado de https://prensacelam.org/2020/04/17/opinion-el-covid-19-castigo-de-dios/

Corpus, A. (2020). Las iglesias, el COVID-19 y la nueva normalidad. Posibilidad Política, $9(23), 37-50$

Dias, E. (3 de abril de 2020). El apocalipsis como revelación: esto enseña la religión sobre el fin de los tiempos. The New York Times. Recuperado de https://www.nytimes.com/ es/2020/04/03/espanol/apocalipsis-coronavirus-religion-rapto.html

Dussel, E. (1998). Historia del fenómeno religioso en América Latina. En. H. Prien (Ed.), Religiosidad e historiografía. La irrupción del pluralismo religioso en América Latina y su elevación metódica en la historiografía (pp. 71-81). Frankfurt-Madrid: Vervuert Verlag/ Iberoamericana.

Eagleton, T. (1997). Ideología. Una introducción. Barcelona: Paidós.

Expreso de Chiapas. (23 de marzo de 2020). Realizan procesión en Chiapas para pedir a santo protección contra coronavirus. Expreso de Chiapas. Recuperado de http:// expresochiapas.com/noticias/2020/03/realizan-procesion-en-chiapas-para-pedir-a-santo-proteccion-contra-el-coronavirus/

Geertz, C. (1989). La interpretación de las culturas. Barcelona: Gedisa.

Houtart, F. (2002). Religiones: sus conceptos fundamentales. México: UNAM-CIICH-Siglo XXI.

Inafed. (2010). Enciclopedia de los municipios y delegaciones de México. Recuperado de http://www.inafed.gob.mx/work/enciclopedia/EMM20oaxaca/municipios/20416a.html

Infobae (18 de mayo de 2020). ¡No tengamos miedo! ante la pandemia de coronavirus, pidió la Iglesia católica mexicana. Infobae. Recuperado de https://www.infobae.com/ america/mexico/2020/05/18/no-tengamos-miedo-ante-la-pandemia-de-coronavirus-pidio-la-iglesia-catolica-mexicana/

INPI. (2020). Atlas de los Pueblos Indígenas de México: Tojolabales-estadísticas. Recuperado de http://atlas.inpi.gob.mx/?page_id=3757 y http://atlas.inpi.gob.mx/?page_ $\mathrm{id}=3061$

IWGIA. (2019). Mundo indígena 2019. Recuperado de https://www.iwgia.org/es/mexico/3381-mi2019-mexico.html

La Jornada. (10 de abril de 2020). Penultimátum. Castigo Divino. La Jornada. Recuperado de https://www.jornada.com.mx/2020/04/10/opinion/a04o1cul

Ley General de Desarrollo Social. (2018). Recuperado de http://www.diputados.gob.mx/ LeyesBiblio/pdf/264_250618.pdf 
Navalón, A. (23 de marzo de 2020). La Torre de Babel y el Virus Vengador. El Financiero. Recuperado de https://www.elfinanciero.com.mx/opinion/antonio-navalon/la-torrede-babel-y-el-virus-vengador

Rivera, S. (17 de abril de 2020). Coronavirus. ¿El principio de un apocalipsis? Experto responde 6 desafiantes preguntas. Los Angeles Times. Recuperado de https://www.latimes.com/espanol/california/articulo/2020-04-17/es-el-coronavirus-el-principio-delfin-del-mundo-ellos-lo-afirman

Ruíz, A. y Limón, F. (2019). Presencia tojolabal en las fiestas patronales de Comitán, Chiapas, México. Noésis. 28(55), 136-171. 